\title{
EVALUATING FRONTAL AUTOMOTIVE BUMPER SYSTEM TO IMPROVE SAFETY
}

\author{
Ahmed. Z. Salem \\ Faculty of Engineering, Civil Eng. Dept.
}

\begin{abstract}
Automotive Frontal bumper systems address two goals. First, is to lessen the inward intrusion during crash scenario and the second is to guarantee pedestrian safety. A good bumper design would try to fulfill these two goals while maintaining its weight as low as feasible to improve energy consumption. In this paper, we try to add to these two functions, a new condition, that is the ability to maintain the minimum possible lasting plastic damage during low speed crashes. This would develop both the crashworthiness of the bumper and the pedestrian safety. We address this condition by assuring that the bumper deformations stay close to the elastic zone of the material. Due to the limited range of the material elastic deformations of the bumper, even at low speeds, we try to complement it with a visco-elastic process. This is achieved by alternating the brackets connecting the bumper to the car structure elements with a spring-dashpot system that provides the desired visco-elastic response, allowing the bumper beam to deform nearly elastically. Finite element analysis is used in the study of the spring-dashpot system parameters to reach the optimum configuration that ensure minimization of plastic deformations in the bumper structure at low speeds of 5 miles/hour crash. The consequence of varying the thickness of the bumper beam is also investigated in this regard. A basic parameterized finite element model of the Ford Crown Victoria bumper form is used in several crash simulations carried out with the explicit dynamics system LS-DYNA3D to test the validity of this bumper system.
\end{abstract}

\section{KEYWORDS: Bumper beam, Impact, crashworthiness simulation, low speed crash.}

\section{INTRODUCTION.}

Automotive crashes always involve loss of money and far more importantly sometimes loss of lives. The annual reports on automotive crashes losses around the world draw a gloomy picture of the current situation. Numerous researches have been made with the aim of reducing such losses and ensure the safety of pedestrians and the car passengers. The most notable research directions revolves around Energy Dissipating Systems [1, 3, 13, 14], occupants safety [2, 4, 7, 8], road safety devices such as Guardrail [5, 8,9], hazards shipment safety during drop tests [6], and structure integrity $[10,11,12,15,17]$.

A common ground in all but [6] is the energy absorption through elasto-plastic process. We consider here a visco-elasto process as an energy absorber system. This system is to replace the supporting brackets connecting the bumper beam to the car structure in the passenger cars.

At low speeds head-on crashes, which do not exceed 5miles/hour, the bumper beam would retract first, towards the car structure within a safe calculated distance to dissipate the energy and then return back to its original position. This system could reduce losses of human injury and money at low speed crashes such as those happening in parking the car or moving in the parking. 
In this paper we investigate the behavior of such system. We study the effect of varying the bumper beam thickness and the damping controlling parameters on the behavior of the system in a head-on crash. The bumper beam metal system is stripped out of cushioning rubber and plastics elements in this investigation to deal with a harsher crash scenario than it would normally be. Those elements would act as an added safety for this system [18].

\section{Finite Element Modeling.}

The Ford Crown Victoria bumper beam is approximated by a symmetric finite element model that has a rectangular cross section with smooth corners as shown in Fig. 1 left. The beam is slightly curves in its lengthwise direction (designated x-axis). Its model is composed of 2600 Belytschko-Tsay shell elements used by LS-DYNA as shown in Fig. 1 right below.

The supporting brackets are replaced by 4 spring-dashpot elements with viscous damping connecting the back of the bumper beam with the car structure, 2 elements at each side. The bumper model is free to move in any direction while the connecting elements are restricted to move only in their longitudinal direction (designated y-axis). They are fixed at the car side and free to move at the bumper beam side. This supporting system is shown in Fig. 1 to the right.

The pedestrian leg is modeled as a cylindrical rigid body. It is modeled by 1600 brick elements of constant-stress solid formulation. This rigid body is impacting the center of the bumper beam perpendicularly with a 5 miles/hour speed. It is restricted also to move only in the $\mathrm{y}$-axis in the car direction. It is shown in Fig. 1 below.
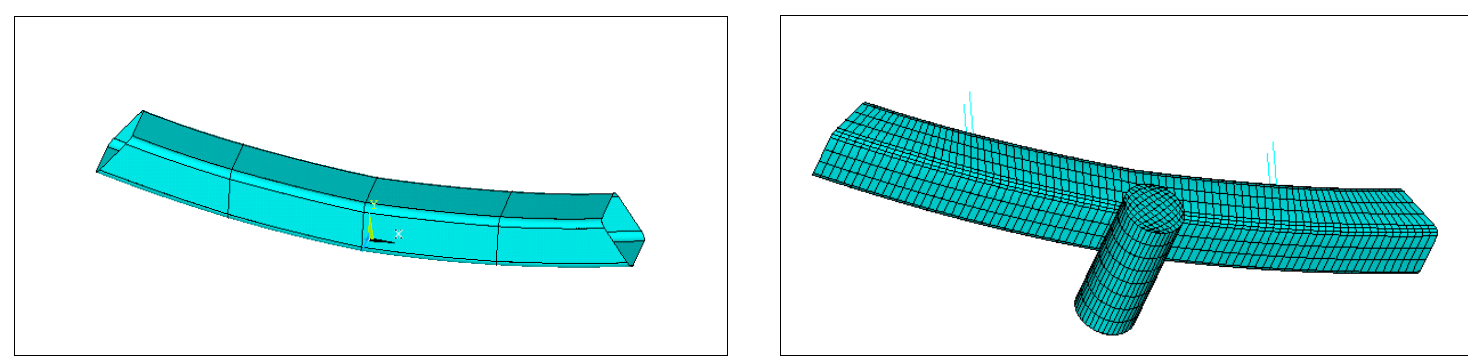

Fig. 1 Finite element model and mesh of the bumper beam, pedestrian leg, and supporting system.

The contact type we used is the automatic general LS-DYNA type. The model is stabilized with hourglass control. A mass scaling mechanism, based on the smallest elements, is used to vanish the deviation in both inertial and momentum effects.

\section{Materials.}

The LS-DYNA material model MAT_PIECEWISE_LINEAR_PLASTICITY is used for the bumper curved beam. The bumper beam is modeled as Commercial Steel bare-CS of $207 \mathrm{GPa}$ for $E, 0.3$ for $v, 190 \mathrm{MPa}$ for yield stress and $7860 \mathrm{~kg} / \mathrm{m}^{3}$ for density.

The Pedestrian leg is modeled as a rigid material with the same properties as Steel above to magnify its effect at the impact investigation. Then, it is used at a much lighter material $(900 \mathrm{~kg} /$ $\mathrm{m}^{3}$ for density) in the final analysis to simulate the human leg. The supporting structure is composed of a spring-dashpot LS-DYAN Discrete elements with $\mathrm{K}=60 \mathrm{E}+05$ and $\mathrm{C}=0.02$ initially.

\section{Bumper Thickness.}

We study first the effect of the bumper beam thickness on both the elastic and plastic strain in it and the rebound displacement of the impactor. We select the thickness to take the values of $4.0 \mathrm{~mm}, 5.0 \mathrm{~mm}$, and $6.0 \mathrm{~mm}$ respectively. The simulation runs for $0.050 \mathrm{sec}$. Fig. 2 below shows the elastic and plastic Von Mises stresses in the bumper at each case. We can see from Fig. 2 that, the front of the bumper beam, facing the impactor experiences both elastic and plastic deformations, while the back of it, facing the supporting system and the car structure mostly deform elastically. It can be seen also that, the thinner the thickness of the bumper beam, the more the plastic deformation takes place.

$\mathrm{dWe}$ focus our attention here on three nodes in the bumper beam, the center node at the face, the 

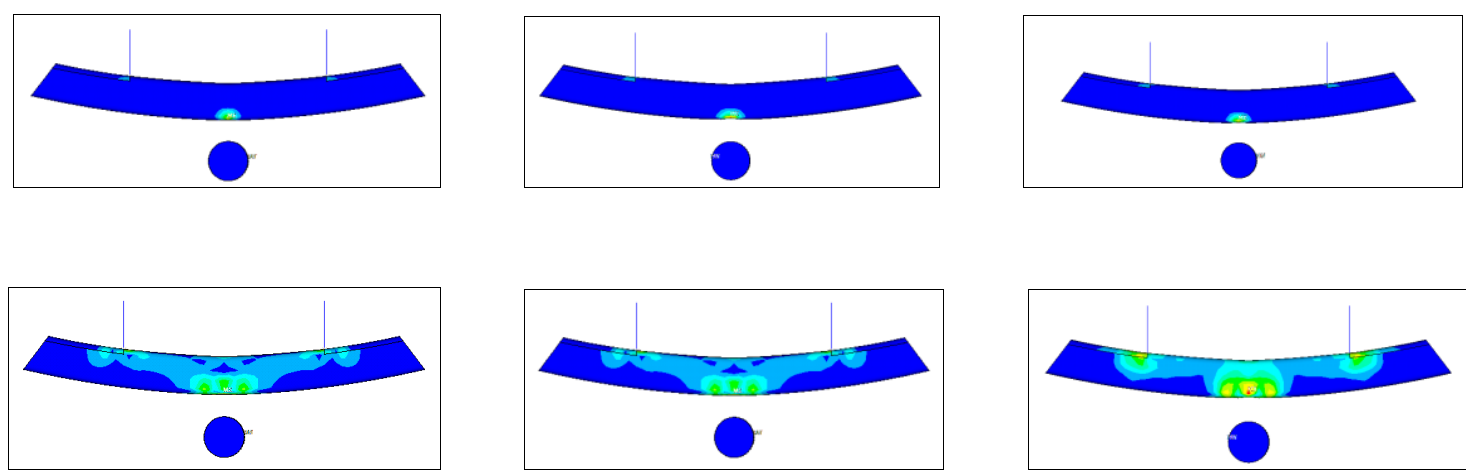

Fig. 2, Plastic (upper) and Elastic (lower) Von Mises Stresses for a bumper beam of 4.0, 5.0, and 6.0 mm thickness from left to right respectively.

node at the supporting element in the back, and its counterpart in the face. Fig. 3 below shows that $y$-axis displacement $(\mathrm{mm})$ of the center node at the face front, facing the impactor, for each thickness. It is displaced as a high pulse first (the bumper is retracting inwardly) then settles to a steady state with permanent plastic deformation. The smaller thickness at the top in the figure shows the most permanent deformation. Fig. 4 shows the same trend of deformation for the node in the face that is opposite to the supporting node, with much less permanent deformation. Fig. 5 shows the same trend of deformation at the back supporting node, but with only elastic deformation as it oscillates around the zero.

Fig. 6 shows the rebound distance of the impactor after the crash, for each thickness. It starts moving towards the bumper beam to close the gap and makes contact, and then it rebounds back under the acquired kinetic energy. The thicker the bumper beam's thickness, the more the rebound distance is. This is because, a stiffer bumper beam deforms mostly elastic (Figs 3 to 5), acting as a sort of spring for the impactor. It would seem from these simulations that the performance of the $5 \mathrm{~mm}$ thickness is a good choice for both predominant elastic deformation and weight minimization of the bumper beam.
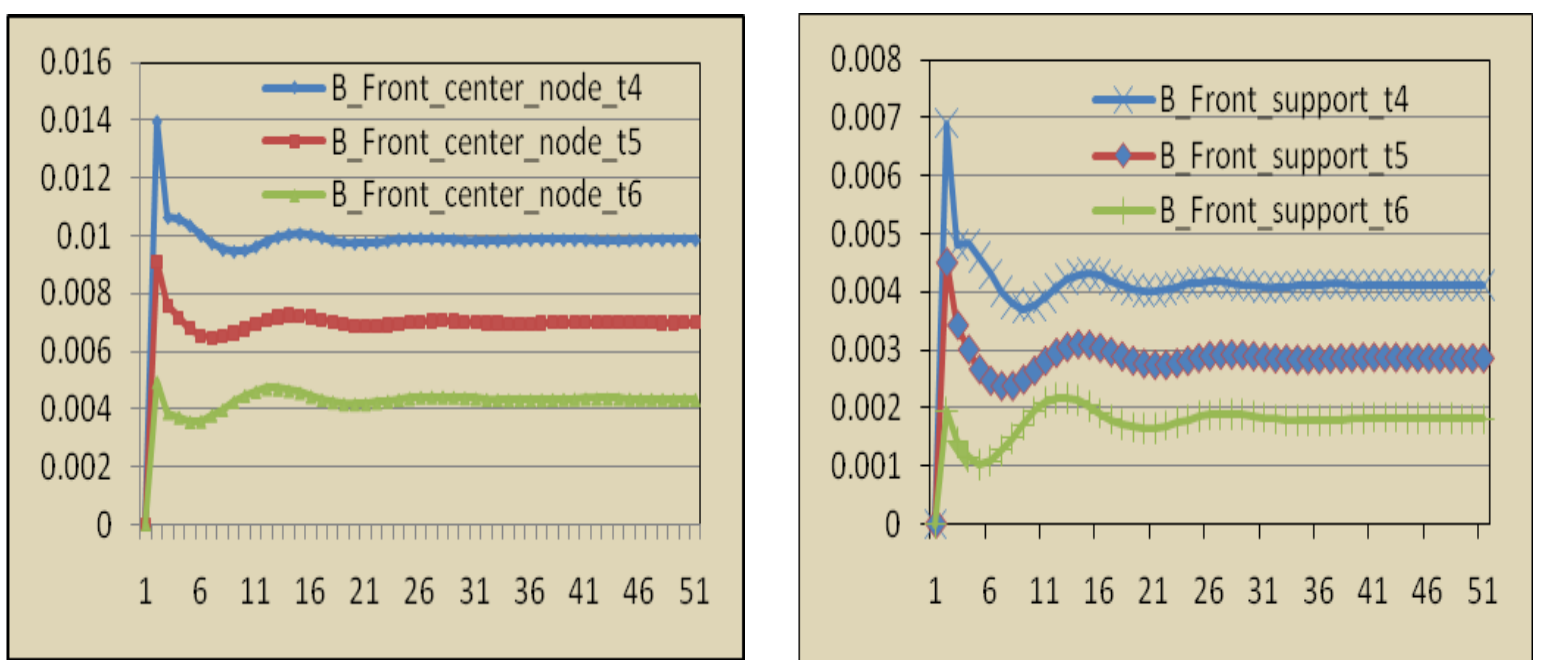

Figs. 3, and 4, displacement in the y direction (Vertical axis, mm) for the bumper beam front support (left), and back support (right) verses the time (Horizontal axis, ms). 

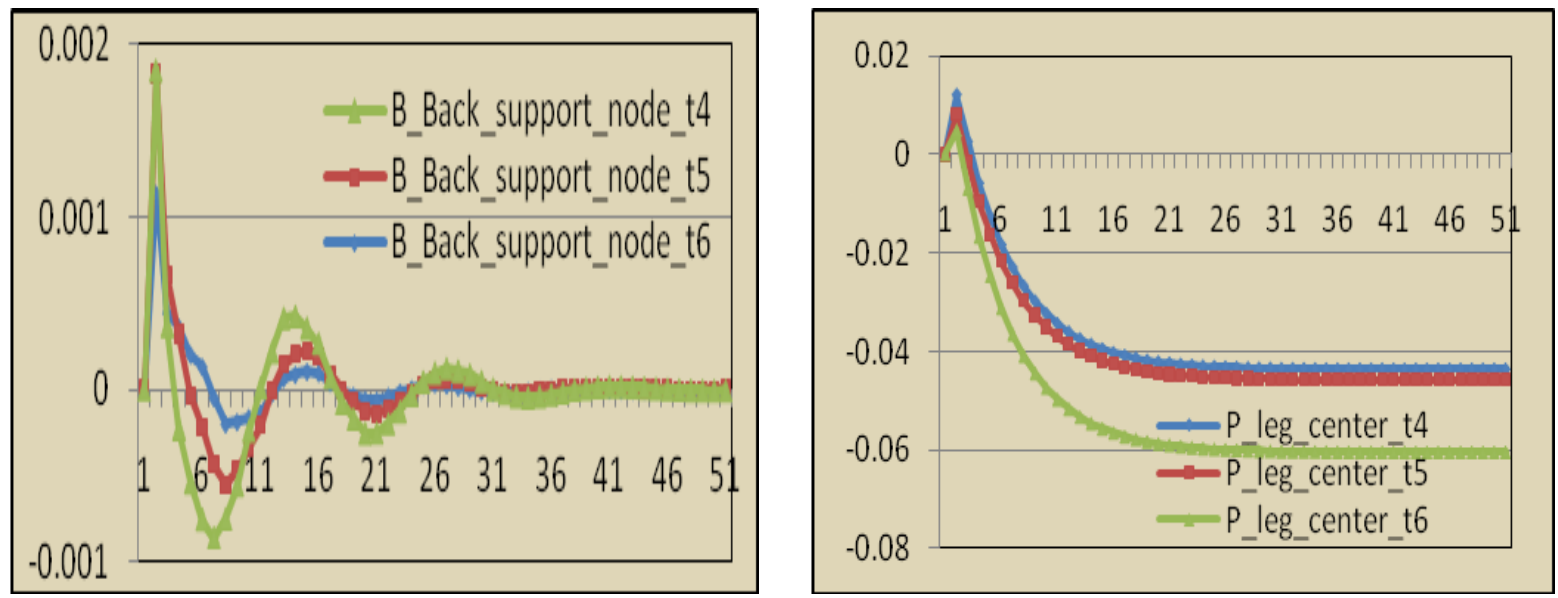

Figs. 5, and 6, displacement in the y direction (Vertical axis, mm) for center node (left) and Pedestrian leg (right) verses the time (Horizontal axis, ms).

\section{Damping Control.}

We fix the bumper beam thickness to $5.0 \mathrm{~mm}$ and examine $\mathrm{C}$ of $.005, .01$, and 0.015 (as 0.02 was used above). Fig. 7 below shows both elastic and plastic Von Mises stresses in the bumper at each case. It is seen from the figure that, the more the damping effect, the stiffer is the bumper beam. This induces more plastic deformation at the bumper front face and less elastic stress with increasing $\mathrm{C}$.
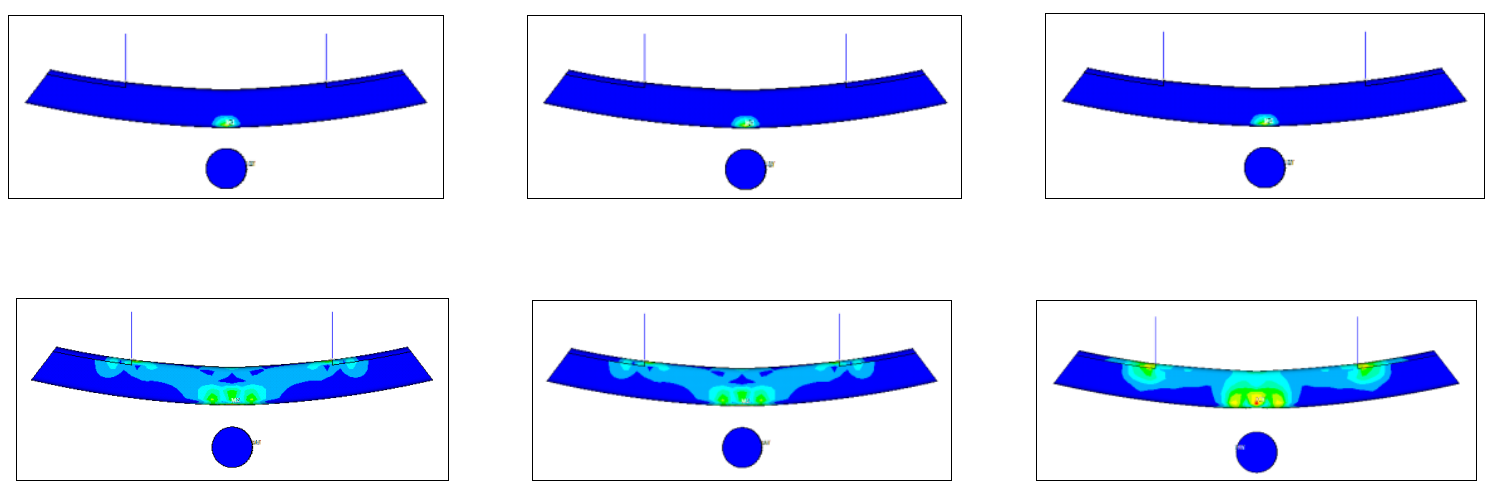

Fig. 7, Plastic (upper) and Elastic (lower) Von Mises Stresses for a bumper beam of 0.005, 0.01, and 0.015 Damping Parameter from left to right respectively.

Fig. 8 below shows the y-displacement at the center front node of the bumper beam for each damping effect. The more the damping effect the less the amplitude of the oscillation occurs. The same trend is evident in Fig. 9 for the back center node which is oscillating around zero. These figures suggest that, $\mathrm{C}$ of 0.02 , as in the previous thickness effect simulations was successful to assure the bumper beam achieving a steady state earlier in the time span.

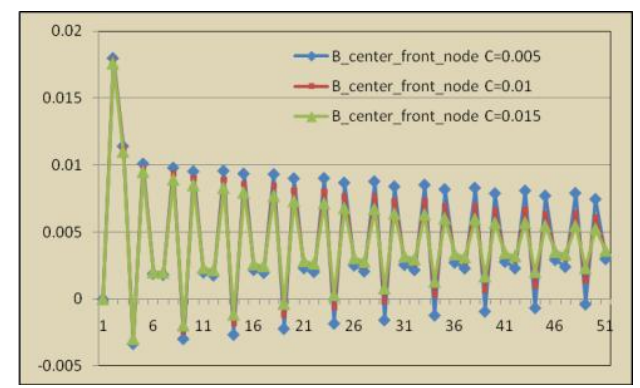

Fig. 8 the displacement in the y direction (Vertical axis, mm) for the bumper beam front center. 


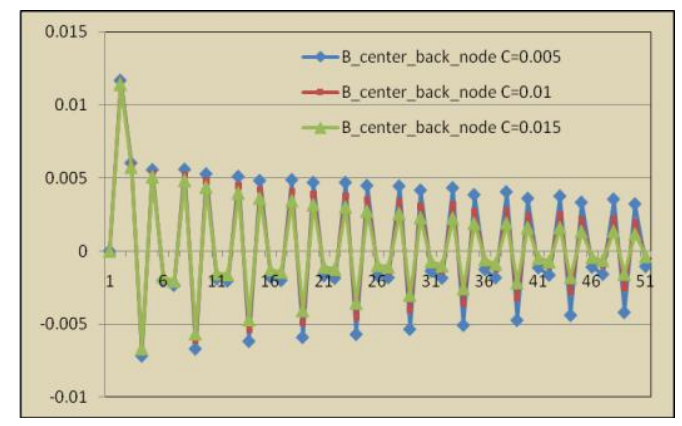

Fig. 9, back support node and verses the time (Horizontal axis, ms).

\section{PROPOSED SYSTEM.}

Based on the effects of thickness and damping variations, we use a thickness of $5.0 \mathrm{~mm}$ and a damping parameter of 0.02 for the final simulation. We reduce the impactor density as mentioned before, but we still consider it rigid to simulate a much worse scenario on the bumper beam. We can see from Fig. 10 below that, all nodes oscillate until they reach the steady state. Both the front and back support nodes oscillate around zero displacement with the front center node keeping a negligible plastic deformation. Should the impactor modeled as a human tissue elastic material, the bumper would suffer almost no plastic deformation.

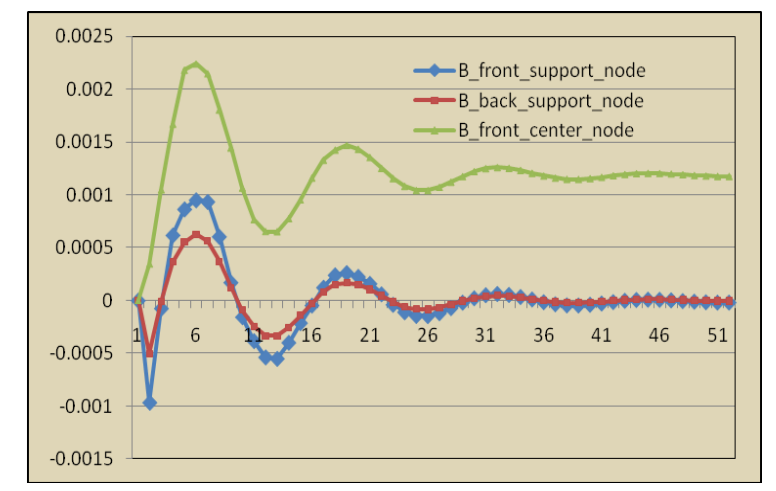

Fig. 10, the displacement in the $y$ direction (Vertical axis, $\mathbf{m m}$ ) for the bumper beam front support node, back support node, and the front center node, verses the time (Horizontal axis, ms).

\section{CONCLUSION.}

We presented an investigation of the behavior of automotive bumper beam that is modeled after the Ford Crown Victoria model, with explicit dynamics. It aims at absorbing the low speed head-on crash energy, through retraction under viscous damping. A study of the effect of varying the bumper beam thickness is presented, to search for a section that is rigid enough to maintain the elastic response and light enough to serve in weight reduction.

A spring-dashpot damping system is proposed as a supporting structure for the beam bumper. The effect of various damping parameter is investigated to reach a damping effect that ensures proper energy absorption for the safety of both the pedestrians and the car. A continuing effort in this direction is undergoing with considering a crash dummy to replace the impactor and a material model simulating human tissues. 


\section{REFERENCES}

[1] W. Johnson, and S.R. Reid, Metallic Energy Dissipating Systems, Applied Mechanics Review, 31 (3), pp. 277-288, 1978.

[2] W. Johnson and A.C. Walton, Protection of Car Occupants in Frontal Impact with Heavy Lorries:

Frontal Structures, International Journal of Impact Engineering, 1 (2), pp. 111-123, 1983.

[3] W. Johnson and A.C. Walton, An Experimental Investigation of the Energy Dissipation of a Number of Car Bumpers under Quasi-Static Lateral Loads, International Journal of Impact Engineering, 1(3), pp. 301-308, 1983.

[4] N. Jones, Some Phenomena in the Structural Crashworthiness Field, International Journal of Crashworthiness, 4 (4), pp. 335-350, 1999.

[5] J.D. Reid and D.L. Sicking, "Design and Simulation of a Sequential Kinking Guardrail Terminal," International Journal of Impact Engineering, 21 (9), pp. 761-772, 1998.

[6] Y. Kanae, T. Sasaki and S. Shimamura, Experimental and Analytical Studies on the Drop-Impact Test with Lead-Shielded Scale Model Radioactive Shipping Casks, In Structural Impact and Crashworthiness, Davies, G. and Morton J.(Eds.), Elsevier, New York, pp. 343-354, 1984.

[7] W. Johnson and A.G. Mamalis (Eds.) Crashworthiness of Vehicles, Mechanical Engineering Publications Limited, London 1978.

[8] G.A.O. Davies and J. Morton (Eds.), Structural Impact and Crashworthiness. Elsevier Applied Science Publishers, New York 1984.

[9] S.R. Reid (Ed.), Metal Forming and Impact Mechanics, Pergamon Press, London, 1985.

[10] T. Wierzbicki and N. Jones (Eds.), Structural Crashworthiness and Failure, John Wiley, New York 1989.

[11] N. Jones, Structural Impact, Cambridge University Press, Cambridge, 1989.

[12] N. Jones and T. Wierzbicki (Eds.), Structural Crashworthiness, Butterworths, London 1983.

[13] J.F. Carney III and S. Pothen, Energy Dissipation in Braced Cylindrical Shells, International Journal of Mechanical Science, 30 (3/4), pp. 203-216 1988.

[14] S.R. Reid, C.D. Austin and R. Smith, Tubular Rings as Impact Energy Absorber, In Structural Impact and Crashworthiness, Davies, G. and Morton, J.(Eds.), Elsevier, New York, pp. 555-563, 1984.

[15] M. Langseth and O.S. Hopperstand, Static and Dynamic Axial Crushing of Square Thin-Walled Aluminum Extrusions, International Journal of Impact Engineering, 18 (7/8), pp. 949-968, 1996.

[16] M. Langseth, O.S. Hopperstand and T. Berstad, Crashworthiness of Aluminum Extrusions: Validation of Numerical Simulation, Effect of Mass Ratio and Impact Velocity, International Journal of Impact Engineering, 22 (8), pp. 829-854, 1999.

[17] P.R. Nannucci, N.S. Marshall and G.N. Nurick, A Computational Investigation of the Progressive Buckling of Square Tubes with Geometric Imperfections, 3ed Asia-Pacific Conference on Shock and Impact Loads on Structures, Singapore, November 24-26, 1999.

[18] J. Marzbanrad, M. Alijanpour, M. SaeidKiasat, Design and analysis of an automotive bumper beam in low-speed frontal crashes, Thin-Walled Structures 47 (2009) 902-911. 